\title{
Determination of Antioxidant Capacity and Total Polyphenol Content of the Extracts from Three Different Parts of Olive Plant and the Green Production of Iron Nano Particles (GInPs)
}

\author{
Ulker Bakir Ogutveren, Fadime Karaer, Esra Findik, and Burcu Kagnicioglu
}

\begin{abstract}
In this study, three different extracts were obtained from the stems, leaves and seeds of the olive plant by ultrasonic method, and the antioxidant capacities and total polyphenol contents of these extracts were determined. Chemical and physical properties of GInPs produced using these extracts were identified.

In order to synthesize GInPs, 5 g sample was extracted in 100 $\mathrm{mL}$ water at $80^{\circ} \mathrm{C}$ during 15 minutes in ultrasonic reactor with $45 \mathrm{kHz}$ frequency. Folin-Ciocalteu method was used for determining anti-oxidant capacity of the extracts and total polyphenol contents were determined by FT-IR (SHIMADZU IRTracer-100 Model) and ATR (Pike Tech). $0.1 \mathrm{M} \mathrm{FeCI}_{3}$ solution as a source of iron was mixed with these extracts using different volumetric ratio to achieve nano-sized iron particle. The size distribution and zeta potential of iron particles produced from each extracts were determined with zetasizer (Malvern 500210). The volumetric ratio of iron solution and these extracts were investigated; these results were correlated with anti-oxidant capacity and total polyphenol content. Final GInPs products image was taken by stereomicroscope (Zeiss Discovery 20).

As a result of this study, it was shown that GInPs ranged from $10 \mathrm{~nm}$ to $100 \mathrm{~nm}$ were produced easily, and the production efficiency was related anti-oxidant capacity and total polyphenol content.
\end{abstract}

Index Terms-Green synthesis, iron nanoparticles anti-oxidant capacity, total polyphenol contents.

\section{INTRODUCTION}

Green synthesis of nanoparticles using various plant extracts containing polyphenols was gained importance thanks to production feasibility with low cost requirement and environmentally friendly methods as an alternative to high technology synthesis methods, which contains toxic, corrosive and hazardous substances with higher cost [1]-[3].

Antioxidants are substances that react with oxygen to remove or delay the negative effects of body and food. Antioxidant substances are very useful for human health. The interest and demand for antioxidant foods has increased recently. The best sources of antioxidants are natural, unprocessed foods such as fruits and vegetables, and vitamins.

Manuscript received April 7, 2018; revised May 24, 2018.

Ulker Bakir Ogutveren and Burcu Kagnicioglu are with the Center for Applied Environmental Research, Anadolu University, Eskisehir, Turkey (e-mail: uogutver@anadolu.edu.tr).

Fadime Karaer is with the Department of Environmental Engineering, Anadolu University, Eskisehir, Turkey.

Esra Findik is with the Center for Applied Environmental Research, Anadolu University, Eskisehir, Turkey.
In addition, the group containing the most antioxidant compound is phenols. Antioxidant capacity were analysed via two methods: hydrogen atom transfer mechanism (HAT) and single electron transfer mechanism (ET). There are various alternatives in HAT and ET-based methods, and the Total Phenol Method with Folin-Ciocalteu separator is one of these methods [4], [5].

Dietary antioxidants such as polyphenolic compounds, vitamins $\mathrm{E}$ and $\mathrm{C}$ and carotenoids are thought to be effective nutrients in the prevention of the oxidative stress-related diseases [6]. Antioxidant activity is expressed as inhibition of ROS-mediated oxidation of the probe or as a selected reference antioxidant equivalent such as troloxacin, ascorbic acid. The oxidation of probes can be measured by various detection technologies. These include spectrophotometric, fluorometric, chemiluminescence, EPR (electron paramagnetic resonance), Fourier transform infrared spectroscopy (FT-IR), NMR (nuclear magnetic resonance) and amperometric methods [7].

In recent years, the use of green synthetic iron nanoparticles (GInPs) has been increasing in environmental remediation. Iron nanoparticles can be prepared by conventional chemical, physical and mechanical methods. However, these conventional methods involve toxic, abrasive and combustible chemical substances, require special equipment and higher costs. Biosynthesis of nanoparticles using plant extracts to solve these problems in conventional synthesis methods; low cost, simple and environmentally friendly alternative method. Various plant extracts contain abundant chemical components such as phenols, reducing sugars, ascorbic acid, which are responsible for the reduction of metal ions and the stabilization of nanoparticles [8]-[10]. It has been shown that metal nanoparticles produced by plants are more stable than those produced by other organisms and that plants (especially plant extracts), fungi and bacteria are reduced more rapidly. Moreover, nanoparticles have more features in shape and size than those produced by other organisms [11].

The purpose of this study is to examine the methods used to determine the antioxidant capacities, phenolic profiles and antioxidant capacities of various parts (leaf, seed and stem) of olive plant. In the first step of the study, plant products were extracted and antioxidant activity and total phenol contents were determined. Folin-Ciocalteu and FT-IR methods were chosen for this purpose. In this study, three different extracts were obtained from the stems, leaves and seeds of the olive plant by ultrasonic method, and the antioxidant capacities and 
total polyphenol contents of these extracts were determined. Chemical and physical properties of GInPs produced using these extracts were identified.

\section{PROCEDURE}

\section{A. Production of Green Iron Nanoparticle by Using Extracts}

In this study, three different extracts were obtained from the stems, leaves and seeds of the olive plant by ultrasonic method. In order to synthesize GInPs, $5 \mathrm{~g}$ sample was extracted in $100 \mathrm{~mL}$ water at $80{ }^{\circ} \mathrm{C}$ during 15 minutes in ultrasonic reactor with $45 \mathrm{kHz}$ frequency before adding 0.1 $\mathrm{M} \mathrm{FeCI}_{3} \cdot 6 \mathrm{H}_{2} \mathrm{O}$ (Merck) as a source of iron. Same trials were made with different volumetric ratio of iron solution and three extracts to produce nano-sized iron particle efficiently. Images of synthesized extracts were illustrated in Fig. 1.

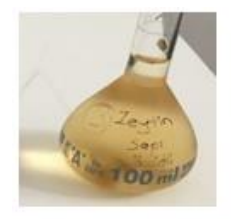

a

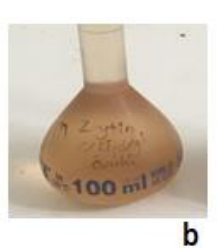

b

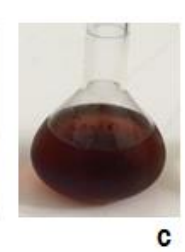

c
Fig. 1. Images of synthesized extracts a: stem, b: seed, c: leaf.

\section{B. Size Distribution of Green Iron Nanoparticle}

In order to determine size distribution of iron particle Zetasizer (Malvern 500210) analysis was performed for each trials. The refractive index was chosen 2.65 for $\mathrm{Fe}_{2} \mathrm{O}_{3}$ compound in GInP solution. In size analysis, GInP solutions were prepared freshly and these solution were sonicated in ultrasonic bath at $45 \mathrm{kHz}$ frequency.

\section{SEM-EDX Analysis of Green Iron Nanoparticle}

In order to characterize GInPs, SEM (Zeiss EVO 40) and EDX (Bruker) analyses were performed for each solution. Each solution were dried at $80^{\circ} \mathrm{C}$ for 1 hour. Gold-palladium coating was made for these samples before SEM-EDX analysis.

\section{Folin-Ciocalteu Method for Determining Anti-oxidant Capacity of the Extracts}

Folin-Ciocalteu method was applied for anti-oxidant capacity of three extracts. Samples prepared by mixing $1 \mathrm{~mL}$ sample, $78 \mathrm{~mL}$ water, $5 \mathrm{~mL}$ Folin-Ciocalteu reactive and 15 $\mathrm{mL} \mathrm{Na}_{2} \mathrm{CO}_{3}(2 \%)$. Prepared samples were centrifuged for 5 minutes at $7000 \mathrm{rpm}$. The absorbance of these samples were read on the spectrophotometer at $760 \mathrm{~nm}$.

\section{E. Total Polyphenol Contents Determination of the Extracts by FT-IR}

The FT-IR technique is based on the vibration of the functional groups present in the sample when exposed to the infrared radiation. In addition, FT-IR is used to determine the total antioxidant capacity (TAC) and total polyphenolic content (TPC) of the samples. When compared to other methods; FT-IR appears superior in terms of efficacy and low analysis duration. The samples prepared were analyzed by FTIR spectrophotometer (SHIMADZU IRTracer-100 Model) with ATR (Pike Tech) which able to use liquid samples without $\mathrm{KBr}$ disk preparation.

\section{RESUlts}

\section{A. Size Distribution and Zeta Potential Results of Green Iron Nanoparticle}

Zetasizer (Malvern 500210) size distribution results were given in Table I. According to the results of size distribution analysis, it was obtained that size of produced GnIPs ranged from $10-10 \mathrm{~nm}$ in the leaf extract solution of $25 \%(\mathrm{v} / \mathrm{v})$. When GnIP solution was not prepared freshly and sonication was not applied, agglomeration occurred in the solution instantaneously.

TABLE I: GREEN IRON NANOPARTICLE SIZE DIISTURBUTION ACCORDING TO FeCI3 PERCENTAGE IN TOTAL SAMPLE Volume

\begin{tabular}{|l|l|l|l|l|}
\hline \multirow{4}{*}{ Sample } & $\begin{array}{l}\text { Percentage } \\
\text { of } \mathrm{FeCI}_{3} \\
(\mathrm{v} / \mathrm{v})\end{array}$ & $\begin{array}{l}\text { Particle size } \\
\text { distribution } \\
(\mathrm{nm})\end{array}$ & $\begin{array}{l}\text { Zeta } \\
\text { Potential } \\
(\mathrm{mV})\end{array}$ & $\begin{array}{l}\text { Mobility } \\
(\mu \mathrm{mcm} / \mathrm{Vs})\end{array}$ \\
\hline \multirow{3}{*}{$\begin{array}{l}\text { Leaf } \\
\text { extract }\end{array}$} & 25 & $10-100$ & 20.33 & 1.4 \\
\cline { 2 - 5 } & 50 & $250-2000$ & 15.4 & 1.5 \\
\cline { 2 - 5 } & 75 & $300-5000$ & 12.5 & 1.9 \\
\hline \multirow{3}{*}{$\begin{array}{l}\text { Seed } \\
\text { extract }\end{array}$} & 25 & $150-5000$ & 14.9 & 1.35 \\
\cline { 2 - 5 } & 50 & $80-800$ & 15.7 & 1.23 \\
\hline \multirow{3}{*}{$\begin{array}{l}\text { Stem } \\
\text { extract }\end{array}$} & 25 & $40-450$ & 17.3 & 1.17 \\
\cline { 2 - 5 } & 50 & $40-1200$ & 7.2 & 0.6 \\
\cline { 2 - 5 } & 75 & $1000-5000$ & 7.5 & 0.5 \\
\hline
\end{tabular}

\section{B. SEM-EDX Analysis Results of Green Iron Nanoparticle}

EDX spectrum of green iron nanoparticles obtained with leaf extract solution of $25 \%(\mathrm{v} / \mathrm{v})$ was given in Fig. 2. The main elements were $\mathrm{C}, \mathrm{Fe}$ and $\mathrm{Cl}$ in EDX spectrum. Also, $\mathrm{O}$, $\mathrm{Ca}, \mathrm{K}, \mathrm{Mg}$, and $\mathrm{Al}$ elements found in GnIP solution. EDX elemental results of green iron nanoparticles were summarized in Table II. This results showed the compounds that can be formed by main elements in EDX spectrum.

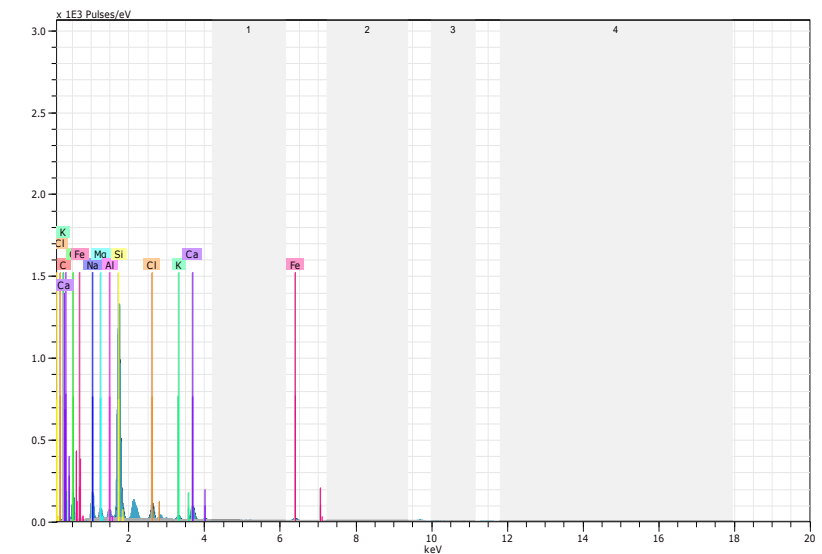

Fig. 2. EDX spectrum of green iron nanoparticle produced with $25 \%$ iron solution and leaf extract.

The result of EDX analysis indicated that GnIPs were produced as $\mathrm{Fe}_{2} \mathrm{O}_{3}$ form. Other compounds observed can be sourced from olive leaves ingredients. SEM images of green iron nanoparticle at $20 \mathrm{kV}$ EHT voltage and $11 \mathrm{~mm}$ working distance with different magnification were given in Fig. 3 . 
TABLE II: EDX RESULTS GNIP SOLUTION

\begin{tabular}{|l|l|l|l|}
\hline \multicolumn{1}{|c|}{ Element } & $\begin{array}{l}\text { Concentration } \\
\text { (wt. })\end{array}$ & Compound & Error \\
\hline Carbon & 3.97 & & 1.4 \\
\hline Oxygen & 42.25 & & 3.8 \\
\hline Sodium & 6.76 & $\mathrm{Na}_{2} \mathrm{O}$ & 0.3 \\
\hline Magnesium & 2.05 & $\mathrm{MgO}$ & 0.1 \\
\hline Aluminum & 1.58 & $\mathrm{Al}_{2} \mathrm{O}_{3}$ & 0.1 \\
\hline Silicon & 30.54 & $\mathrm{SiO}_{2}$ & 0.9 \\
\hline Chlorine & 3.94 & & 0.1 \\
\hline Potassium & 1.30 & $\mathrm{~K}_{2} \mathrm{O}$ & 0.1 \\
\hline Calcium & 5.21 & & 0.1 \\
\hline Iron & 2.41 & & 0.1 \\
\hline
\end{tabular}

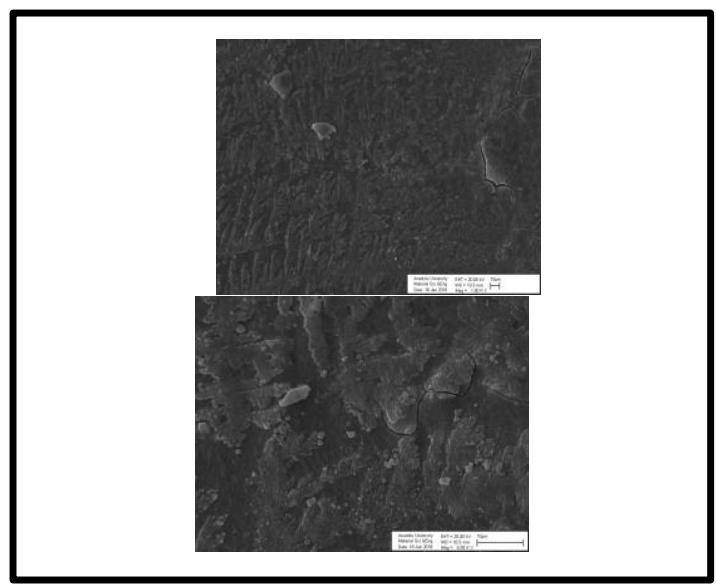

Fig. 3. SEM result GInPs a:1000x, b:5000x, c:10000x,d:50000x.

SEM images demonstrated that size distribution of GnIPs ranged smaller than $1 \mu \mathrm{m}$. Also, it was clearly obtained from these images that GnIPs were agglomerated.

\section{Anti-oxidant Capacity of Extracts Using \\ Folin-Ciocalteu Method}

Anti-oxidant capacity of extracts were determined with Folin-Ciocalteu Method using gallic acid calibration indicated anti-oxidant capacity related phenol content. Calibration graph was shown in Fig. 4. The results of anti-oxidant capacity of each extract was summarized in Table III.

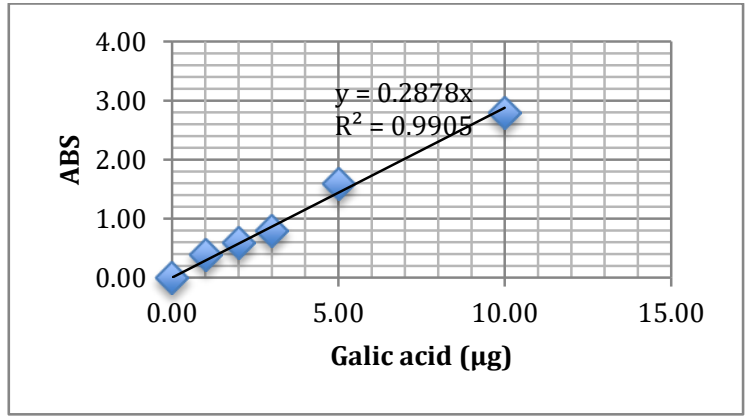

Fig. 4. Gallic acid calibration curve.

TABLE III: THE RESULT OF ANTI-OXIDANT CAPACITY OF EACH EXTRACT

\begin{tabular}{|c|c|c|}
\hline Sample & ABS & Galic acid $(\mu \mathrm{g})$ \\
\hline Leaf extract & 0,263 & 0.91 \\
\hline Seed extract & 0,133 & 0.46 \\
\hline Stem extract & 0,083 & 0.29 \\
\hline
\end{tabular}

\section{Total Polyphenol Contents Determination of the Extracts by FT-IR}

Total polyphenol contents determined by FT-IR were shown in Fig. 5.

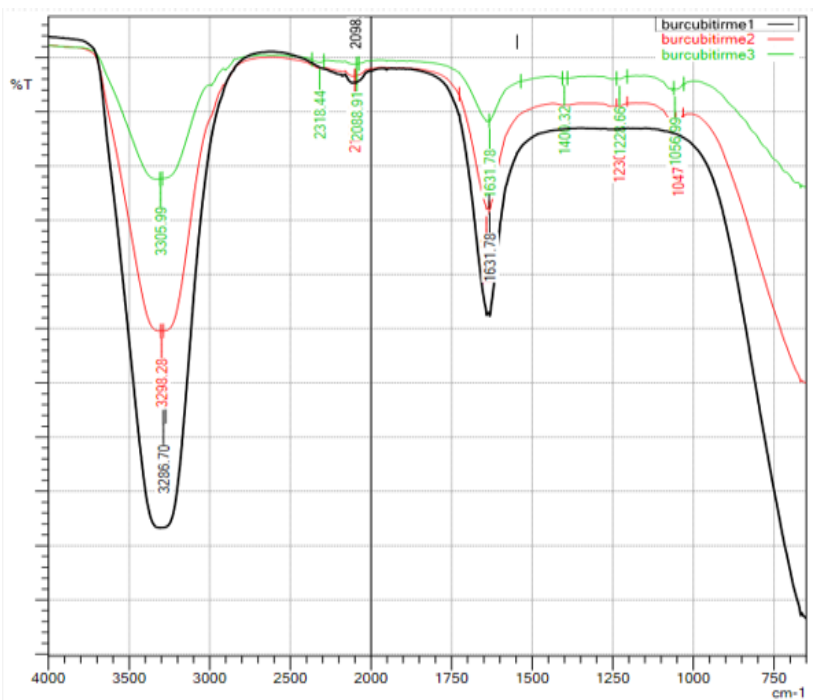

Fig. 5. FT-IR result (green: stem, red: seed, black: leaf).

\section{CONCLUSION}

As a result of this study, it was shown that GInPs ranged from $10 \mathrm{~nm}$ to $100 \mathrm{~nm}$ were produced successfully using an environmentally friendly, green manufacturing process. It was observed that the nano particles produced were disposed at agglomeration. Production in an ultrasonic bath can be proposed to overcome this drawback.

Production efficiency of GInPs was found to be related anti-oxidant capacity as gallic acid and total polyphenol content of the extracts. The results showed that the gallic acid content was the higher value of $0.91 \mu \mathrm{g}$ and the fraction of polyphenolic compounds was nearly $25 \%(\mathrm{v} / \mathrm{v})$ in leaf extract. The maximum efficiency of GInPs production was achived using olive leaf extract due to this highest anti-oxidant capacity and total polyphenol content comparing the other parts of the olive.

\section{REFERENCES}

[1] E. Masarovicova and K. Kral'ova, "Metal nanoparticles and plants," Ecological Chemistry and Engineering S-Chemia I Inzynieria Ekologiczna S, vol. 20, no. 1, pp. 9-22, 2013.

[2] P. S. Chowdhury, P. R. Arya, and K. Raha, "Green synthesis of nanoscopic iron oxide particles: A potential oxidizer in nanoenergetics," Synthesis and Reactivity in Inorganic Metal-Organic and Nano-Metal Chemistry, vol. 37, no. 6, pp. 447-451, 2007.

[3] M. Stefaniuk, P. Oleszczuk, and Y. S. Ok, "Review on nano zerovalent iron (nZVI): From synthesis to environmental applications," Chemical Engineering Journal, vol. 287, pp. 618-632, 2016.

[4] P. Schofield, D. M. Mbugua, and A. N.Pell, "Analysis of condensed tannins: A review." Anim. Feed Sci. Tech., vol. 91, pp. 21-40, 2001.

[5] Council of Europe, Determination of tannins in herbal drugs. In European Pharmacopoeia, 6th ed.; European Directorate for the Quality of Medicines: Strasbourg, France (2007) A286.

[6] D. Huang, B. Ou, and R. L. ve Prior, "The chemistry behind antioxidant capacity assays," Journal of Agricultural and Food Chemistry, vol. 53, pp. 1841-1856, 2005.

[7] F. Shadidi and Y. ve Zhong, "Measurement of antioxidant activity," Journal of Functional Foods, vol. 18, pp. 757-781, 2015.

[8] S. Machado, S. L. Pinto, and J. P. Grosso, and H. P. A. Nouws, J. T. Albergaria, and C. ve Delerue-Matos, "Green production of 
zero-valent iron nanoparticles using tree leaf extracts," Science of the Total Environment, vol. 445-446, pp. 1-8, 2013.

[9] S. Iravani, "Green synthesis of metal nanoparticles using plants," Green Chemistry, vol. 13, pp. 2638-2650, 2011.

[10] S. S. Ali, N. Kasoju, A. Luthra, A. Singh, H. Sharanabasava, A. Sahu, and U. ve Bora, "Indian medicinal herbs as sources of antioxidants," Food Research International, vol. 41, pp. 1-15, 2008.

[11] L. K. MacDonald-Wicks, L. G. Wood, and M. L. ve Garg, "Methodology for the determination of biological antioxidant capacity in vitro: A review," Journal of the Science of Food and Agriculture, vol. 86, pp. 2046-2056, 2006.

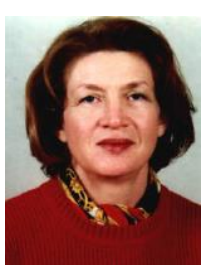

Ülker Bakir Ogutveren is a professor at Anadolu University, Department of Environmental Engineering and head of Center for Applied Environmental Research in Eskisehir, Turkey. She has numerous publications about electrochemical treatment method for environmental remediation in high impact factor journal.

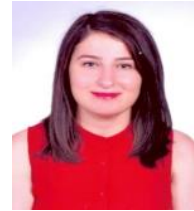

F adime Karaer is a senior researcher at Anadolu University, Department of Environmental Engineering in Eskisehir, Turkey. She has started $\mathrm{PhD}$ education in Institute of Science, Anadolu University and she has been working water pollution and treatment.

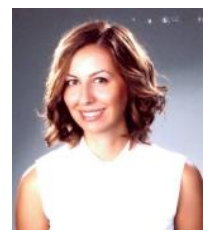

Esra Findik is a senior researcher at Anadolu University, Department of Environmental Engineering in Eskisehir, Turkey. She has started PhD education in Institute of Science, Anadolu University and she has been working water pollution and treatment.

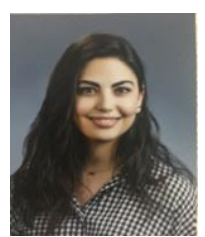

Burcu Kagnicioglu is master student in Anadolu University Institute of Science and she has been working on water pollution and treatment. 